\title{
Sikap Jepang Terhadap Korea Selatan Terkait Agreement On Comfort Women 2015
}

\author{
Beti Regina Ratri \\ Erna Kurniawati \\ email : betyregina26@gmail.com \\ Prodi Hubungan Internasional FISIP UPN "Veteran" Yogyakarta \\ J1. Babarsari No.2, Tambakbayan, Yogyakarta
}

\begin{abstract}
Jugun ianfu or comfort women is a term for women who were recruited by the Japanese Government during the Japanese military occupation in World War II which was used as a slave to sexual of Japanese military. The desire of the victims, especially in South Korea to get responsibility and justice rights for the treatment of Japanese military in the past, demanded that Japan respond to various demand. Japan has tried various responses in fulfilling demands, the one is Agreement on Comfort Women 2015 but there have been various criticisms and rejections of the response so that the problem of this issue cannot be resolved. This article aims to discuss how Japan responds to the demands of ex-comfort women in South Korea. The method used is library research and qualitative research.
\end{abstract}

Keywords: Jugun Ianfu, Comfort Women, Japan, Republic of Korea.

\section{Pendahuluan}

Salah satu konflik yang terjadi antara Jepang dan Korea Selatan adalah terkait permasalahan tuntutan para mantan jugun ianfu di Korea Selatan. Jugun ianfu adalah sebutan bagi para wanita Asia yang direkrut oleh Pemerintah Jepang pada masa kependudukan tentara Jepang pada Perang Dunia II dan dijadikan budak nafsu seksual bala tentara Jepang (Sartini, 2003: 149). Sikap kedua negara dalam merespons tindakan dan kebijakan dalam menyelesaikan permasalahan ini menjadikan hubungan antar keduanya menjadi konfliktual.

Teori yang digunakan dalam penelitian ini adalah teori politik internasional. Politik internasional menurut Holsti adalah sebuah studi mengenai pola tindakan negara terhadap lingkungan eksternal sebagai reaksi atas respons negara lain. Politik 
internasional menggambarkan hubungan dua arah, menggambarkan reaksi dan respons dari suatu negara (Perwita, 2005: 40). Respons yang timbul akan berkaitan dengan terbentuknya sebuah sikap terhadap peristiwa atau objek tertentu. Sikap mempunyai efek penting tentang bagaimana para pembuat kebijakan memberi reaksi atau merespons tindakan, isyarat, dan permintaan negara lain, merasakan kehendak pemerintah lain, dan menentukan tujuan mereka sendiri terhadap pihak lain (Holsti, 1998: 88). Kasus mengenai permasalahan jugun ianfu di Korea Selatan akan membuktikan asumsi dasar dari teori politik internasional yaitu melalui respons dan interaksi kedua negara, dimana dalam penelitian ini akan lebih difokuskan dari sisi Jepang.

\section{Latar Belakang Konflik}

Ketika Jepang berhasil memenangkan perang Cina-Jepang (1894-1895) dan perang Rusia-Jepang (1904-1905), Jepang melakukan intervensi ke Korea secara paksa dan mulai menjajah Korea (Yoon, 2003: 136). Jepang melakukan berbagai kekejaman terhadap rakyat Korea yang pada saat itu masih terintegrasi menjadi satu negara salah satunya adalah pembentukan comfort station atau ianjo. Comfort station pertama kali dibangun pada tahun 1932 di Shanghai Cina oleh Okamura Yasuji yang merupakan Wakil Kepala Staf Pasukan Ekspedisi Shanghai pada waktu itu (Witt, 2016: 21). Berdasarkan data yang diperoleh dari website Kementerian Luar Negeri Jepang, negaranegara yang pernah dibangun ianjo adalah Jepang, Cina, Filipina, Indonesia, Malaya, Thailand, Burma (Myanmar), Papua Nugini, Hongkong, Makau dan Indocina Perancis (https://www.mofa.go.jp/policy/postwar/issue9308.html). Dalam comfort station terdapat sebuah sistem yang bernama jugun ianfu.

Secara harfiah pengertian jugun ianfu terdiri atas empat kata yaitu " ju" berarti ikut, "gun" berarti militer, "ian" berarti penghibur, dan " $f u$ " berarti perempuan, sehingga jugun ianfu berarti perempuan penghibur yang ikut militer (Suliyati, 2018: 42). Jugun ianfu atau dalam bahasa Inggris disebut comfort women merupakan sebutan bagi para wanita yang direkrut oleh Pemerintah Jepang pada masa kependudukan tentara Jepang selama perang Asia Pasifik dan dijadikan budak nafsu seksual bala tentara Jepang. Para jugun ianfu ini sebagian direkrut dari wilayah Asia yaitu wilayah 
jajahan Jepang pada masa Perang Asia Pasifik dengan berbagai cara seperti ditipu, diculik, dibeli dari keluarga miskin atau terikat hutang, dan dikumpulkan dengan melibatkan pihak-pihak tertentu. Perempuan-perempuan yang dijadikan jugun ianfu harus memiliki kriteria kesehatan yang baik, sedangkan perempuan yang tidak memenuhi kriteria kesehatan akan dipekerjakan di tempat lain seperti restoran, rumah makan, tempat hiburan, hotel atau rumah tangga petinggi-petinggi militer Jepang.

Jugun ianfu memiliki perbedaan dengan perempuan pekerja seks dalam sistem prostitusi. Perbedaan antara kedua istilah tersebut dapat dibedakan berdasarkan tiga unsur yaitu transaksi, promiskuitas, dan ketidakacuhan emosional (Hartono, 1997: 85). Dalam sistem prostitusi terdapat proses transaksi atau pembayaran upah kepada perempuan pekerja seks, sedangkan dalam sistem jugun ianfu tidak ada proses transaksi yang terjadi karena dilakukan dengan keterpaksaan. Unsur promiskuitas dalam sistem prostitusi menunjukkan praktik hubungan seksual yang dilakukan sesaat antara sejumlah pria dan wanita tanpa adanya aturan yang mengikat atau dengan kata lain dilakukan dengan siapa saja, sedangkan dalam sistem jugun ianfu bersifat terbatas karena jugun ianfu hanya melakukan hubungan dengan orang Jepang. Unsur ketidakacuhan emosial dalam sistem prostitusi bermakna bahwa ketika perempuan pekerja seks melakukan pekerjaannya mereka sekedar melayani dan tidak memiliki komitmen apapun kecuali sebuah pembayaran atas jasa layanan seks yang telah diberikan, sedangkan dalam sistem jugun ianfu, para wanita melakukan pekerjaannya secara paksa di bawah ancaman Jepang sehingga tidak ada ikatan emosional yang terjalin dalam hubungan tersebut.

Isu jugun ianfu mulai muncul pada Agustus 1991 yaitu ketika adanya kesaksian dari salah satu mantan jugun ianfu bernama Kim Hak Sun dari Korea Selatan yang memberikan kesaksian bahwa ia merupakan korban atas sistem jugun ianfu oleh Jepang dan menceritakan penderitaannya ketika dipaksa menjadi seorang jugun ianfu. Sejak saat itu, kesaksian dari para mantan jugun ianfu mulai bermunculan. Munculnya kesaksian dari para mantan jugun ianfu diikuti oleh gugatan kepada Jepang untuk menuntut beberapa hal, yaitu: 
1. Permintaan maaf secara langsung kepada para mantan jugun ianfu dan kepada publik.

2. Pemberian kompensasi dana rehabilitasi mantan jugun ianfu.

3. Mencari, meneliti dan mengungkapkan bukti-bukti yang tersedia.

4. Mengutuk upaya untuk memfitnah korban atau menyangkal peristiwa jugun ianfu.

5. Pengakuan formal terhadap sejarah akan keberadaan jugun ianfu.

6. Pemberian tuntutan dan tanggung jawab hukum bagi para pelaku kejahatan sistem ianjo.

7. Mendirikan sebuah monumen peringatan bagi korban perbudakan seksual militer Jepang dan membangun museum bersejarah.

\section{Metode Penelitian}

Penelitian ini menggunakan metode penelitian kualitatif dengan teknik analisis data deskriptif kualitatif. Dimana data-data yang diperoleh dan dikumpulkan lebih berupa kata-kata dan gambar-gambar bukan merupakan angka-angka (Bakry, 2017: 19). Data yang diperoleh akan dikaji untuk menjelaskan fenomena jugun ianfu di Korea Selatan, kemudian menganalisa sikap Jepang terhadap Korea Selatan terkait Agreement on Comfort Women 2015 berdasarkan dukungan data dan fakta tersebut.

\section{Hasil Penelitian}

\section{Sikap Jepang Terhadap Tuntutan Mantan Jugun Ianfu Sebelum Adanya Agreement On Comfort Women 2015}

Pada Juli 1992, Pemerintah Jepang menerbitkan laporan pertama mengenai jugun ianfu yang mengakui bahwa terdapat keterlibatan pemerintah dalam menjalankan sistem jugun ianfu selama Perang Dunia II (Hui, 2010: 141). Namun dalam laporan tersebut disebutkan bahwa Pemerintah Jepang tidak menemukan bukti adanya unsur paksaan yang diberikan kepada jugun ianfu untuk melayani nafsu biologis para tentara Jepang. Hal tersebut kemudian menuai kritik dari beberapa negara Asia khususnya Korea Selatan yang akhirnya membuat Pemerintah Jepang melanjutkan penyelidikannya. 
Pada Agustus 1993, sebuah pernyataan resmi oleh Pemerintah Jepang melalui Kepala Sekretaris Kabinet Yohei Kono mengakui tanggung jawab Jepang atas adanya peristiwa perbudakan seksual oleh militer Jepang dan meyampaikan permintaan maaf kepada semua mantan jugun ianfu (https://www.mofa.go.jp/policy/women/fund/ state9308.html). Pernyataan Yohei Kono menyebutkan bahwa sistem comfort station dioperasikan secara langsung maupun tidak langsung oleh otoritas militer pada saat itu dan perekrutan jugun ianfu dilakukan oleh para perekrut khusus atas permintaan militer Jepang, bahkan terkadang direkrut secara langsung oleh militer Jepang dengan cara dibujuk atau dipaksa.

Pada 31 Agustus 1994, Perdana Menteri Tomiichi Murayama menyatakan penyesalan dan permintaan maaf atas permasalahan jugun ianfu pada masa Perang Dunia II, dan mendirikan Asian Women's Fund (AWF) pada Juli 1995. (http://www.awf.or.jp/pdf/0170.pdf). AWF merupakan sebuah lembaga yang memiliki tugas untuk melaksanakan proyek bersama antara pemerintah dan masyarakat Jepang untuk mengumpulkan dana yang digunakan sebagai pembayaran kompensasi atas kekejaman yang telah dilakukan Jepang pada masa Perang Dunia II, mempromosikan proyek-proyek yang menyatakan penebusan dosa perang oleh Pemerintah Jepang kepada mantan jugun ianfu, serta mempromosikan proyek-proyek lain untuk menyelesaikan masalah kontemporer yang dihadapi jugun ianfu.

Namun kritik terhadap proyek yang dilaksanakan oleh AWF banyak bermunculan dari para mantan jugun ianfu, kelompok aktivis pembela jugun ianfu dan kelompok-kelompok masyarakat Jepang yang berpandangan sama. Kritik tersebut muncul karena kompensasi dana yang diberikan kepada mantan jugun ianfu tidak secara langsung dari dana pemerintah namun berasal dari dana yang diperoleh dari sumbangan masyarakat. Hal tersebut membuat AWF tidak dapat menyelesaikan permasalahan jugun ianfu yang berada di Korea Selatan yaitu hanya bertahan selama lima tahun sejak 11 Januari 1997 hingga 1 Mei 2002. (http://awf.or.jp/e3/korea.html).

Pada kepemimpinan PM Shinzo Abe, respons yang dilakukan oleh Jepang bertentangan dengan respons sebelumnya. Pada 1 Maret 2007, PM Shinzo Abe 
membuat sebuah pernyataan yang menyangkal adanya bukti yang menunjukkan bahwa para jugun ianfu dipaksa untuk menjadi budak seks para tentara Jepang serta adanya upaya untuk merevisi pernyataan mantan sekretaris kabinet Yohei Kono atau sering disebut Pernyataan Kono pada tahun 1993 (Dudden, 2007: 1). Pernyataan PM Shinzo Abe tersebut menuai reaksi dari berbagai kalangan baik dalam negeri maupun luar negeri. Dari dalam negeri surat protes ditujukan kepada PM Shinzo Abe oleh Japan Action Network for The Comfort Women Issue yang didampingi oleh tiga perwakilan diet. Sedangkan dari dunia internasional pada 31 Januari 2007 Mike Honda yang merupakan salah satu anggota Dewan Perwakilan Rakyat AS mengusulkan House Resolution $\quad 121 . \quad$ (https://www.congress.gov/110/ bills/hres121/BILLS110hres121eh.pdf). Resolusi tersebut memuat beberapa tuntutan yang harus dipenuhi oleh Jepang yang berkaitan dengan pertanggung jawaban Jepang terhadap isu jugun ianfu.

\section{Japan-Republic Of Korea Agreement On Comfort Women 2015}

Pengesahan House Resolution 121 membuat beberapa negara Eropa dan Asia lainnya ikut mendukung dengan mengeluarkan resolusi yang sama di Belanda pada 8 November 2007, Kanada pada 18 November, Parlemen Uni Eropa pada 12 Desember 2017, Korea Selatan pada 27 Oktober 2008, dan Taiwan pada 11 November 2008. Selanjutnya protes secara besar-besaran kepada Jepang juga dilakukan oleh berbagai NGO dan masyarakat dunia yang dilaksanakan pada 14 Desember 2011 bertepatan dengan peringatan 1000 hari Wednesday demonstration yang merupakan aksi protes kepada Jepang oleh para mantan jugun ianfu di Korea Selatan dan para aktivis pembela hak-hak sipil Korea Selatan setiap hari Rabu di depan Kantor Kedutaan Jepang di Seoul. Dimana dalam aksi tersebut, didirikan sebuah patung jugun ianfu atau Pyeonghwa-bi di depan Kantor Kedutaan Besar Jepang di Seoul.

Selain itu, Presiden Park Geun-Hye juga menyatakan bahwa tidak akan mengadakan pertemuan bilateral secara formal dengan PM Shinzo Abe selama Pemerintah Jepang belum meminta maaf secara tulus dan memberikan kompensasi kepada para mantan jugun ianfu di Korea Selatan (Adityani, 2008: 26). Hal tersebut 
mendesak Jepang untuk menyelesaikan masalah jugun ianfu di Korea Selatan dikarenakan kedua negara memerlukan hubungan kerjasama yang baik untuk menghadapi ancaman uji coba nuklir Korea Utara.

Sehingga pada 28 Desember 2015 Menteri Luar Negeri Jepang Fumio Kishida dan Menteri Luar Negeri Korea Selatan Yun Byung-Se mengumumkan sebuah perjanjian bernama Japan-ROK Agreement on Comfort Women 2015 pada acara konferensi pers setelah adanya pertemuan antara kedua menteri tersebut. Kedua Menteri Luar Negeri menyampaikan pernyataannya masing-masing. Menteri Luar Negeri Jepang, Fumio Kishida menyampaikan beberapa poin atas perjanjian tersebut, yaitu: (https://www.mofa.go.jp/a_o/na/kr/page4e 000365._html).

1. Pemerintah Jepang menyadari tanggung jawabnya dan meminta maaf kepada para mantan jugun ianfu.

2. Pemerintah Korea Selatan mendirikan sebuah yayasan rehabilitasi para mantan jugun ianfu dengan pemberian dana satu kali oleh Jepang sebanyak 1 miliar yen yang diambil dari dana anggaran Jepang serta proyek-proyek-proyek rehabilitasi dilakukan di bawah kerjasama antara Pemerintah Jepang dan Korea Selatan.

3. Pemerintah Jepang menegaskan bahwa permasalahan ini telah diselesaikan secara final dan tidak dapat diubah serta kedua negara akan menahan diri untuk tidak saling menuduh atau mengkritik masalah tersebut pada masyarakat internasional termasuk PBB.

Kemudian Perdana Menteri Korea Selatan Yun Byung-se juga mengumumkan pernyataannya dalam tiga poin penting, yaitu: (http://www.mofa.go.kr/eng/brd/ m_5674/ view.do?seq=319622).

1. Menegaskan bahwa permasalahan tentang jugun ianfu telah diselesaikan secara final dan tidak dapat diubah atas dasar bahwa langkah-langkah yang telah dinyatakan oleh Pemerintah Jepang diterapkan dengan setia

2. Pemerintah Korea Selatan akan melakukan upaya yang tepat untuk menyelesaikan permasalahan patung jugun ianfu yang didirikan di depan Kantor Kedutaan Jepang di Seoul 
3. Pemerintah Korea Selatan dengan Pemerintah Jepang akan menahan diri untuk tidak saling menuduh atau mengkritik pada forum internasional termasuk di PBB dengan syarat bahwa langkah-langkah yang dinyatakan oleh Jepang diimplementasikan dengan setia.

Perjanjian tersebut kemudian ditegaskan kembali oleh kedua pemimpin negara yaitu PM Shinzo Abe dan Presiden Park Geun-Hye melalui telepon pada tanggal yang sama setelah adanya pernyataan dari kedua Menteri Luar Negeri. Agreement on Comfort Women 2015 antara Jepang dan Korea Selatan telah menandai adanya inisiatif yang dibuat oleh kedua negara agar permasalahan terkait jugun ianfu dapat terselesaikan dengan mengarah pada hubungan yang berorientasi dimasa depan. Namun belum mencapai satu tahun pasca disepakati, perjanjian antar kedua negara telah mendapatkan kritik dan penolakan dari para korban dan para pembela HAM khususnya dalam isu perbudakan seksual militer Jepang.

Dalam sebuah laporan pada tahun 2016 yang ditulis oleh Women's Active Museum on War and Peace (WAM) yang merupakan organisasi non pemerintah dan juga museum yang berfokus pada isu kekerasan terhadap perempuan pada masa perang khususnya masalah jugun ianfu menyebutkan beberapa alasan tentang penolakan Agreement on Comfort Women 2015, alasan tersebut antara lain: (https://tbinternet. ohchr.org/Treaties/CEDAW/Shared\%20Documents/JPN/INT_CEDAW_NGO_JPN_23 078_E.pdf).

1. Perjanjian disepakati tanpa berkonsultasi dengan para korban.

2. Tidak ada dokumen tertulis yang menyatakan bahwa para korban dapat menyetujui atau menandatangani perjanjian tersebut.

3. Pertanyaan tentang tanggungjawab yang disampaikan Jepang dalam perjanjian.

4. Tidak ada permintaan maaf kepada para korban secara langsung.

5. Tidak dijelaskannya pencarian fakta lebih lanjut dan penerusan fakta sejarah melalui pendidikan.

6. Karakteristik pemberian dana 1 miliar yen yang dibayarkan satu kali tanpa adanya perbaikan. 
7. Pemenuhan tuntutan para korban melalui rekomendasi yang ditujukan kepada Jepang.

Selanjutnya Jepang menerima surat dari Pelapor Khusus Komisi HAM PBB yang meminta penjelasan kepada Jepang terkait dengan beberapa tuntutan yang diajukan oleh para mantan jugun ianfu dan para pembela HAM pada 19 April 2016. Menanggapi pertanyaan tersebut, Pemerintah Jepang mengirim surat balasan yang berisi : (https://www.mofa.go.jp/files/000235398.pdf).

1. Mengenai tuntutan untuk menyelidiki semua kasus, menuntut dan menghukum pelaku serta mengungkapkan semua bukti yang tersedia, Pemerintah Jepang telah melakukan studi pencarian fakta secara menyeluruh tentang masalah jugun ianfu sejak awal tahun 1990an ketika masalah tersebut diangkat menjadi masalah politik antara Jepang dan Korea Selatan.

2. Mengenai tuntutan untuk menghukum pelaku dan adanya kejahatan perang yang dilakukan oleh warga Jepang, Pemerintah Jepang menganggap bahwa sangat sulit menyelidiki fakta-fakta dari kasus-kasus individual secara retrospektif sehingga Pemerintah Jepang tidak mempertimbangkan untuk menuntut dan menghukum pelaku.

3. Mengenai tuntutan untuk memberikan kompensasi penuh kepada para korban dan keluarganya, Pemerintah Jepang telah dengan tulus menangani masalah kompensasi, properti dan klaim yang berkaitan dengan Perang Dunia II di bawah Perjanjian San Francisco, melalui perjanjian-perjanjian dan instrumen bilateral.

4. Mengenai tuntutan mengutuk upaya untuk mencemarkan nama baik korban atau untuk menyangkal peristiwa, Pemerintah Jepang tidak berniat untuk menyangkal masalah jugun ianfu.

5. Mengenai tuntutan mendidik siswa melalui referensi dalam buku teks, Pemerintah Jepang menganggap isu tersebut terdapat dalam pedoman untuk kursus studi yang menyediakan standar desain kurikulum sekolah.

6. Pada 28 Juli 2016 Pemerintah Korea Selatan telah mendirikan sebuah yayasan untuk mendukung kesejahteraan para mantan jugun ianfu dan Pemerintah Jepang 
telah memberikan dana sejumlah 1 miliar yen (USD 8.9 juta) kepada yayasan tersebut pada 31 Agustus 2016.

Berbagai upaya telah dilakukan Jepang untuk menyelesaikan masalah jugun ianfu dan merespons tuntutan-tuntutan yang diberikan oleh mantan jugun ianfu dan masyarakat internasional. Namun berbagai upaya tersebut masih belum sepenuhnya diterima dan belum mampu memenuhi tuntutan para korban, khususnya dalam Agreement on Comfort Women 2015 yang bersifat final dan tidak bisa diubah. Banyak terdapat kritik dan penolakan terhadap perjanjian tersebut meski ada pula yang menyetujui adanya perjanjian itu.

\section{Penarikan Duta Besar Dan Konsuler Jepang Di Korea Selatan}

Para mantan jugun ianfu di Korea Selatan melakukan berbagai aksi untuk mendapatkan perhatian Pemerintah Jepang dan masyarakat dunia agar tuntutannya dapat segera terpenuhi. Bersama Korean Council for The Women Drafted for Military Sexual Slavery by Japan atau dalam bahasa Korea disebut Jeongdaehyeob yang merupakan organisasi pembela hak dalam isu perbudakan seksual militer oleh Jepang, melakukan kampanye Wednesday demonstration dan mendirikan patung jugun ianfu (Pyeonghwa-bi) di depan kantor Kedutaan Jepang di Seoul. Jepang menganggap bahwa pendirian patung Pyeonghwa-bi tersebut merupakan sebuah tindakan yang merendahkan martabat dan citra Jepang. Anggapan tersebut mengacu pada pasal 22 ayat 2 Konvensi Wina tahun 1961. Sehingga Pemerintah Jepang meminta Pemerintah Korea untuk menyelesaikan permasalahan patung tersebut. Namun kelompok-kelompok sipil yang diorganisir oleh Jeongdaehyob telah membuat sebuah pernyataan yang menyebutkan bahwa patung Pyeonghwa-bie tidak terikat pada suatu kondisi atau suatu perjanjian apapun dan Pemerintah Korea Selatan tidak memiliki wewenang apapun untuk pemindahan patung tersebut. Pernyataan tersebut semakin membuat Pemerintah Korea Selatan kesulitan dalam melaksanakan tanggung jawabnya yang telah disepakati dalam Agreement on Comfort Women 2015.

Pada akhir Desember 2016, patung Pyeonghwa-bi kembali didirikan didekat Kantor Konsulat Jenderal Jepang di Busan. Melalui Kepala Sekretaris Kabinet 
Yoshihide Suga, Jepang memberikan pernyataan sikap untuk merespons pendirian patung tersebut dalam sebuah konferensi pers yang menyatakan bahwa Jepang menarik Duta Besar Yasumasa Nagamine dan Konsul Jenderal Jepang Yasuhiro Morimoto di Korea Selatan untuk sementara waktu menghentikan partisipasi staf konsuler dalam acara-acara yang diselenggarakan oleh kota Busan, menghentikan konsultasi tentang pengaturan pertukaran mata uang antara Jepang dan Korea Selatan, serta menunda dialog ekonomi tingkat tinggi. (https://japan.kantei.go.jp/tyoukanpress/201701/ 6_a.html). Penarikan Duta Besar Yasumasa Nagamine dan Konsul Jenderal Jepang Yasuhiro Morimoto dilakukan sejak Januari 2017 hingga April 2017. Jepang menganggap bahwa tindakan tersebut merupakan sebuah pelanggaran dalam Agreement on Comfort Women 2015 yang telah disepakati dan merupakan sebuah aksi penghinaan diplomatik.

\section{Penolakan Jepang Terhadap Kritikan Presiden Moon Jae-In Melalui Sikap Konsistensi Jepang Dalam Agreement on Comfort Women 2015}

Pergantian pemimpin di Korea Selatan dari Presiden Park Geun-Hye kepada Presiden Moon Jae-In membuat isu jugun ianfu kembali memanas karena keduanya memiliki perbedaan pandangan terhadap isu tersebut khususnya dalam Agreement on Comfort Women 2015 dan terdapat pola hubungan yang berbeda antara keduanya dalam menyelesaikan permasalahan isu tersebut. Pada masa Presiden Park Geun Hye, penempatan isu lebih cenderung berpusat pada interaksi antara Pemerintah Korea Selatan dengan Pemerintah Jepang. Presiden Park Geun-Hye menganggap bahwa permasalahan jugun ianfu dapat terselesaikan melalui sebuah perjanjian yang bersifat final dan tidak dapat diubah yaitu Agreement on Comfort Women 2015.

Sedangkan pada masa kepemimpinan Presiden Moon Jae-In, penyelesaian permasalahan tersebut lebih berorientasi pada tuntutan para mantan jugun ianfu dan berusaha agar tuntutan tersebut dipenuhi oleh Jepang sesuai dengan apa yang dikehendaki oleh para korban. Terkait dengan Agreement on Comfort Women 2015, Presiden Moon Jae-In memandang bahwa perjanjian tersebut tidak dapat menyelesaikan masalah jugun ianfu. Pandangan tersebut didasari oleh anggapan bahwa perjanjian itu 
tidak cukup mencerminkan pendapat para mantan jugun ianfu dan perlu meninjau kembali perjanjian tersebut. Presiden Moon Jae In menganggap bahwa perjanjian tersebut merupakan sebuah kesalahan dalam pengambilan kebijakan yang dilakukan oleh pemimpin Korea Selatan yang konservatif. Sehingga pada masa kepemimpinannya, Kementerian Luar Negeri Korea Selatan membentuk satuan satuan tugas peninjauan kembali perjanjian Korea Selatan-Jepang tentang masalah korban jugun ianfu yang bertugas untuk meninjau dan menilai proses dan substansi dari perjanjian tersebut.

Hasil peninjauan dari satuan tugas di bawah Kementerian Luar Negeri Korea Selatan tersebut menunjukkan beberapa fakta yang menjelaskan bahwa perjanjian tersebut tidak seimbang dan memberikan beban kewajiban yang lebih besar kepada Korea Selatan, Jepang menyetujui tuntutan utama para mantan jugun ianfu secara tidak sukarela dengan beberapa persyaratan, perjanjian tersebut mengesampingkan kebutuhan dan tuntutan para mantan jugun ianfu, dan kekuatan pengambilan keputusan kebijakan dalam proses negosiasi terlalu terkonsentrasi pada Kantor Kepresidenan.

Laporan Hasil peninjauan oleh satuan tugas tersebut kemudian direspons oleh Pemerintah Jepang berdasarkan pernyataan oleh Menteri Luar Negeri Jepang Taro Kono pada 27 Desember 2017 yang menegasakan bahwa perjanjian tersebut dibentuk melalui proses negosiasi yang sah antara Pemerintah Jepang dan Korea Selatan. (https://www.mofa.go.jp/press/release/press4e_001857.html). Oleh karena itu, Jepang merasa bahwa tidak ada masalah dalam proses perjanjian tersebut.

Selain itu Pemerintah Jepang juga menegaskan posisinya bahwa apabila Korea Selatan akan mengubah perjanjian yang telah diimplementasikan maka hubungan Jepang dan Korea Selatan akan menjadi tidak terkendali dan hal tersebut tidak akan diterima oleh Jepang. Dengan kata lain, Jepang menolak adanya perubahan dalam Agreement on Comfort Women 2015 yang telah diimplementasikan oleh kedua negara. Pemerintah Jepang akan mendesak Korea Selatan untuk memastikan penerapan perjanjian yang bersifat final dan tidak dapat diubah.

Namun respons Jepang tidak dipenuhi oleh Korea Selatan. Hasil peninjauan oleh satuan tugas membuat Korea Selatan mempertimbangkan kembali Agreement on 
Comfort Women 2015. Pada 21 November 2018, Pemerintah Korea Selatan melalui Kementerian Kesetaraan Gender dan Keluarga mengumumkan sebuah pernyataan bahwa proyek Yayasan Rekonsiliasi dan Penyembuhan yang dibentuk oleh Pemerintah Korea Selatan pada era kepemimpinan Presiden Park Geun-Hye dibubarkan. (http://www.asahi.com/ajw/articles/AJ201811210059.html). Proyek yayasan tersebut merupakan bagian dari kewajiban Pemerintah Korea yang disepakati dalam Agreement on Comfort Women 2015 dan telah didanai oleh Jepang sebesar 1 miliar yen. Yayasan tersebut banyak mendapatkan kritikan yang mengatakan bahwa pembentukan yayasan merupakan cara yang tidak efektif bagi Jepang dalam menebus kesalahan masa lalunya.

Atas kebijakan tersebut, PM Shinzo Abe merespons dengan mengungkapkan kekecewaannya terhadap keputusan Pemerintah Korea Selatan. PM Shinzo Abe meminta agar Korea Selatan menghormati perjanjian yang telah disepakati oleh kedua negara pada 2015. Respons yang dilakukan Jepang kemudian adalah Wakil Menteri Luar Negeri Jepang, Takeo Akiba memanggil Duta Besar Korea Selatan untuk Jepang, Lee Su-hoon yang dilakukan untuk mengajukan pernyataan bahwa Jepang tidak dapat menerima keputusan mengenai pembubaran proyek yayasan tersebut. (https://asia.nikkei.com/Politics/ International-relations/Tokyo-and-Seoul-drift-furtheras-comfort-women-foundation-dies).

Pemerintah Jepang melalui Menteri Luar Negeri Taro Kono juga menegaskan bahwa Agreement on Comfort Women 2015 adalah komitmen internasional. Jepang telah memenuhi kewajiban dan tanggung jawabnya berdasarkan perjanjian dan mengharapkan bahwa Korea Selatan dapat mengambil tindakan yang seharusnya dilakukan sebagaimana diatur dalam perjanjian tersebut.

Yayasan rekonsiliasi yang berdiri sejak 28 Juli 2016 hingga 21 November 2018 oleh Pemerintah Korea Selatan telah menggunakan dana dari Jepang sebesar 1 miliar yen untuk melaksanakan proyek-proyeknya. Namun setelah dibubarkan, yayasan tersebut masih menyisakan dana dari dana rehabilitasi yang telah diberikan oleh Jepang. Pemerintah Korea Selatan mengatakan bahwa akan mengadakan perundingan dengan Jepang untuk membahas mengenai sisa dana yayasan tersebut. Namun hingga saat ini, 
kedua negara belum melakukan perundingan untuk membahas masalah tersebut dikarenakan hubungan kedua negara sedang memburuk sejak adanya keputusan dari Mahkamah Agung Korea Selatan yang menyatakan bahwa beberapa perusahaan Jepang diharuskan membayar ganti rugi kepada orang Korea yang menjadi tenaga kerjanya pada masa pendudukan kolonial Jepang. Permasalahan baru yang timbul menjadikan perundingan dalam menyelesaikan masalah jugun ianfu menjadi tertunda dan belum mencapai penyelesaian yang benar-benar bersifat final.

\section{Simpulan}

Respons Jepang dalam memenuhi tuntutan mantan jugun ianfu hingga menyepakati Agreement on Comfort Women 2015 dengan Korea Selatan belum memberikan hasil yang signifikan karena dalam perjanjian tersebut masih menimbulkan perselisihan antara kedua negara. Keputusan kebijakan yang diambil oleh kedua negara tidak seutuhnya mampu memberikan solusi yang tepat karena kedua belah pihak tidak mengorientasikan perjanjian pada kepentingan dan tuntutan para korban. Selain itu tidak adanya dokumen tertulis yang menyatakan persetujuan dari para mantan jugun ianfu membuat kredibilitas perjanjian tersebut menjadi dipertanyakan.

Rekonsiliasi yang telah diupayakan ke dua negara akan sulit mencapai win win solution ketika ke dua negara tidak memberikan orientasi pemenuhan kepentingan para korban. Apabila ke dua negara belum memiliki pandangan yang sama dalam memandang isu tersebut, maka penyelesaiannya akan semakin berlarut-larut. Terlebih lagi, penyelesaian pasca dibubarkannya yayasan rekonsiliasi yang dibentuk oleh Korea Selatan menggunakan dana dari Jepang menjadi lambat dan tertunda karena muncul permasalahan baru yang juga terkait dengan isu sejarah.

\section{Referensi:}

\section{Buku}

Perwita Anak Agung Banyu dan Yayan Mochamad Yani. (2005). Pengantar Ilmu Hubungan Internasional, Bandung, Remaja Rosdakarya. 
Holsti, K.J. (1998). Politik Internasional: Kerangka Untuk Analisis Jilid 2, Terj. M. Tahir Azhary, Jakarta, Penerbit Erlangga.

Yoon, Yang Seung dan Nur Aini Setiawati. (2003). Sejarah Korea Sejarah Awal Abad Hingga Masa Kontemporer, Yogyakarta, Gadjah Mada University Press.

Hartono, Budi, Dadang Juliantoro, Rosalia Sciortino (ed.). (1997). Derita Paksa Perempuan Kisah Jugun Ianfu Pada Masa Pendudukan Jepang, 1942-1945, Cetakan 1, Jakarta, Pustaka Sinar Harapan.

Bakry, Umar Suryadi, (2017). Metode Penelitian Hubungan Internasional, Edisi 2, Yogyakarta, Pustaka Pelajar.

Hui, Lim Kim. (2010). Masalah Wanita Penghibur Jugun Ianfu: Antara Kriminalitas, Martabat Bangsa, Dan Permainan Semantik, dalam Mukhtasar Syamsuddin, Nur Aini Setiawati, dkk. (ed.), Sejarah Korea Menuju Masyarakat Modern: Beberapa Peristiwa Penting, Yogyakarta, INAKOS.

\section{Jurnal}

Sartini. (2003). Kontradiksi Dalam Asumsi Religiusitas Pada Bangsa Jepang: Telaah Filosofis Pergeseran Makna Religi, Jurnal Filsafat, 34(2), hal. 147-157.

Witt Ms., Kathryn J. (2016). Comfort Women: The 1946-1948 Tokyo War Crimes Trials and Historical Blindness, The Great Lakes Journal of Undergraduate History, 4(1), 15-33.

Suliyati, Titiek. (2018). Jugun Ianfu: Derita Perempuan Dalam Pusaran Perang, Jurnal Kiryoku, 2(3), 41-49.

Dudden, Alexis dan K Mizoguchi. (2007). Abe's Violent Denial: Japan's Prime Minister and the Comfort Women, The Asia-Pacific Journal, 5(3), 1-2.

Adityani, Fiandara Dwi. (2008). Memori Dan Trauma Dalam Hubungan Internasional: Pengaruh Isu Comfort Women Terhadap Kerjasama Keamanan Jepang Dan Korea Selatan, Journal of International Relations, 4(1), 22-30.

\section{Website}

Cabinet Councillors' Office on External Affairs, "On the Issue of Comfort Women". Tersedia dari: https://www.mofa.go.jp/policy/postwar/issue 9308.html.

Ministry of Foreign Affairs of Japan, "Statement by the Chief Cabinet Secretary Yohei Kono on the Result of the Study on the Issue of Comfort Women". Tersedia dari: https://www.mofa.go.jp/policy/women/fund/state9308.html.

Asian Women's Fund, “The Comfort Women Issue and the Asian Women's Fund". Tersedia dari: http://www.awf.or.jp/pdf/0170.pdf. 
Asian Women's Fund, "Project by Country or Region-South Korea”. Tersedia dari: http://awf.or.jp/e3/korea.html.

United States House of Representatives, "House Resolution 121 Tersedia dari: https://www.congress.gov/110/bills/hres121/BILLS-110hres121eh.pdf.

Ministry of Foreign Affairs of Japan, "Japan-ROK Foreign Ministers' Meeting December 28 2015". Tersedia dari: https://www.mofa.go.jp/a_o/na/ kr/page4e_000365.html.

Ministry of Foreign Affairs of Republic Of Korea, "Remarks at the Joint Press Availability December 28, 2015". Tersedia dari: http://www.mofa.go.kr/ eng/brd/m_5674/view.do?seq=319622.

Women's Active Museum on War and Peace, “Japan Military Sexual Slavery NGO Alternatives Information to the Government Reply to the List of Issues". Tersedia dari: https://tbinternet.ohchr.org/Treaties/CEDAW /Shared\%20Documents/JPN/INT_CEDAW_NGO_JPN_23078_E.pdf.

Ministry of Foreign Affairs of Japan, "Reply of the Government of Japan to the Letter Sent by the Special Rapporteur for Follow up to Concluding Observations of the Human Rights Committee Dated 19 April 2016". Tersedia dari: https://www.mofa.go.jp/files/000235398.pdf.

Cabinet Secretariat of Japan, "Press Conference of the Chief Cabinet Secretary". Tersedia dari: https://japan.kantei.go.jp/tyoukanpress/201701/6_a.html.

Ministry of Foreign Affairs of Japan, "Announcement of the Results of the Assessment by the Taskforce to Review the Agreement on Comfort Women Issue Reached Between the Governments of Japan And the ROK (Statement by Foreign Minister Taro Kono". Tersedia dari: https://www.mofa.go.jp/press /release/press4e_001857.html.

Takeda, Hajimu dan Yoshihiro Makino, "Seoul to Disband Comfort Women Foundation: Abe Blasts Decision". Tersedia dari: http://www.asahi.com /ajw /articles/AJ201811210059.html.

Onchi, Yosuke, "Tokyo And Seoul Drift Further As Comfort Women Foundation Dies". Tersedia dari: https://asia.nikkei.com/Politics/International-relations /Tokyo-and-Seoul-drift-further-as-comfort-women-foundation-dies. 